\title{
¿PARA QUÉ Y PARA QUIÉNES SE ORGANIZAN LAS AGENDAS DE INVESTIGACIÓN RURAL? PRODUCCIÓN DE CONOCIMIENTOS Y SEMILLAS (O APUNTES EN FAVOR DE UNA TEORÍA CRÍTICA DE LA CIENCIA)
}

\author{
Cecilia Gárgano
}

\section{INTRODUCCIÓN}

Quien monopoliza la producción y el abastecimiento de las semillas controla la alimentación, en otras palabras, controla la vida. Las semillas son, también, reservorio ancestral de culturas e identidades, por lo que cualquier movimiento que las implique avanza también sobre cosmovisiones y lazos comunitarios. Y, al mismo tiempo, ellas son, cada vez más, la punta de lanza para el acceso a una serie concatenada de nichos comerciales que integran los famosos "paquetes tecnológicos", extremadamente rentables e igualmente concentrados por pocas firmas en todo el mundo. Como señala Dominique Pestre (2005), en las últimas décadas, la legislación sobre patentes y la jurisprudencia que la acompañó extendieron ampliamente el campo de aplicación del patentamiento y constituyeron una vía privilegiada de acceso para modificar equilibrios anteriores, haciendo prevalecer la norma de la mercantilización como la única eficaz. Armando Bartra (2006) denominó a estas lógicas asociadas al crecimiento de la biotecnología como "la renta de la vida". A su vez, estas racionalidades impregnaron tanto los laboratorios de las universidades, como las agendas y recursos de los organismos públicos orientados al desarrollo rural. En este sentido, cabe preguntarnos, ¿por qué dentro de la problemática de la privatización de las semillas vale la pena problematizar también la producción de conocimientos científicos y tecnológicos asociados a ellas, y su mercantilización? En primer lugar, 
estos conocimientos inciden diariamente en nuestras vidas. Qué comemos, cómo enfermamos, qué curas se nos ofrecen, cómo se trabajan los suelos y qué escenarios futuros se construyen, son solo algunas de las cuestiones vitales que atraviesan. ¿No vale la pena, entonces, reflexionar sobre sus condiciones de existencia hoy? ¿Nos da igual una ciencia empresarial al servicio de las corporaciones a una que se funde en necesidades sociales? ¿Es esto último posible? Al saber tecnológico racional y eficientista, anclado en la concepción de la ciencia occidental como único saber legítimo, ¿es posible contraponer otros? ¿No necesitamos pugnar por instancias de participación que nos permitan tener incidencia en cómo se organizan recursos y agendas de investigación que afectan tan fuertemente nuestros cotidianos? Si cinco décadas atrás la revolución verde transformó para siempre los patrones de producción y consumo a lo largo del mundo, el actual proceso de imbricación entre ciencias de la vida, tecnología y mercados está generando transformaciones aún más profundas. En este caso, además, sin haber logrado la mentada productividad en el incremento de la cantidad de alimentos, ni el abaratamiento de sus costos. Por esto pensar formas de trabajar y habitar la tierra alternativas a los "desiertos verdes" que se expanden por América Latina también demanda discutir ciencia para qué y para quiénes. Por esta razón, este capítulo se dedica a analizar dinámicas de producción de conocimientos científicos y tecnológicos asociados a la obtención de semillas en América Latina, haciendo foco en Argentina.

El primer apartado realiza una breve síntesis sobre el lugar que ocupan conocimientos y naturaleza en la literatura sobre los comunes, planteando la necesidad de analizar en forma sincrónica los patrones extractivistas de acumulación presentes en la región y los modos que asume la producción de conocimiento científico. El segundo, realiza una reconstrucción histórica que se remonta a los comienzos de la revolución verde y a la organización de organismos públicos enfocados al desarrollo rural y a la tecnología agropecuaria, y avanza por los conflictos recientes en materia de legislación de saberes y semillas. Finalmente, en las conclusiones se puntualizan los resultados y se generan interrogantes en torno a la necesidad de alimentar una teoría crítica de la ciencia que ponga en cuestión tanto sus dimensiones políticas, económicas y sus valores, como la voz de las poblaciones implicadas en las decisiones científicas y tecnológicas.

\section{BIENES COMUNES NATURALES, CONOCIMIENTO CIENTÍFICO Y EXTRACTIVISMO}

La noción de "bienes comunes" es una definición de carácter teóricopolítico, que aboga por una relación no mercantilista y comunitaria de aquellos recursos básicos para la supervivencia y reproducción 
social de las comunidades (Helfrich y Haas, 2008). La denominación alude metafóricamente a las common lands, las tierras de uso común existentes durante el medioevo europeo, en las que existían dinámicas comunitarias de producción y un heterogéneo esquema de relaciones de reciprocidad. Mientras que la transición del feudalismo al capitalismo tuvo en el proceso de cercamiento de tierras un hito fundamental, la literatura que aborda el estudio de los comunes ha analizado diversos procesos contemporáneos, que avanzan en la privatización de elementos fundamentales para el desarrollo de la vida humana. Estos conflictos involucran nuestros modos de habitar, nuestras prácticas cotidianas y el incesante avance de las leyes del capital hacia nuevos espacios, otrora impensados. Movimiento que, en términos de Boyle (2003), puede ser entendido como un segundo cercamiento.

Dentro del enfoque de los comunes, una gran cantidad de trabajos analizan la producción de conocimiento desde el punto de vista de la producción académica, los sistemas de acceso abierto, la generación y apropiación de datos informáticos, y diversos procesos enmarcados en la era del denominado "capitalismo cognitivo" (Vercellone, 2013; Mouiler Boutang, 2012, entre otros). Por otro lado, otra serie de estudios analizan la apropiación de los bienes comunes naturales, como el agua, la tierra, los minerales, la energía y las semillas (Bollier, 2008). En estos últimos, los conocimientos originados por comunidades indígenas y campesinas han recibido una gran atención, ligada a la histórica expropiación de estos saberes. Por el contrario, la apropiación de conocimientos científicos vinculados a la naturaleza y generados con fondos públicos en los institutos de investigación de América Latina ha sido poco explorada. Sin embargo, también su dinámica de producción se encuentra directamente asociada a conflictos provocados por las tensiones entre las matrices productivas vigentes, y los modos diferenciados de acceso a los bienes comunes naturales. En esta oportunidad nos proponemos abordar una transición entre ambos ejes, analizando la producción cognitiva asociada a las semillas. También el conocimiento, científico en este caso, es entendido como un bien común. Esto implica reparar en que éste es resultado de una construcción colectiva e histórica que también es crecientemente "cercada", mercantilizada, y cuyas definiciones y prioridades no están por fuera de la disputa social, más bien todo lo contrario.

En este sentido, partimos de la necesidad de sostener y construir una teoría crítica de la ciencia, por dos razones. En primer lugar, porque consideramos que este enfoque es necesario para analizar las vinculaciones entre ciencia, tecnología y problemáticas sociales y ambientales. En segunda instancia, porque apostamos a que también 
pueda funcionar como herramienta de intervención contra-hegemónica. Esto no implica considerarla como una solución a estas problemáticas, ni desconocer los límites que implica que el saber científico y tecnológico sean una pieza clave del desarrollo capitalista, sino más bien problematizar el modo en el que pueda aportar en estas disputas, buscando operar en los intersticios que existen en todo bloque dominante. ¿Qué entendemos, entonces, por "teoría crítica de la ciencia"? ¿Y qué alcances y problemas enfrenta esta caracterización en nuestros territorios?

Si bien los estudios que abordan la cuestión científica y tecnológica son muy amplios tanto disciplinar (historia, filosofía, antropología y sociología de la ciencia) como analíticamente, y desde diversos ángulos han sido planteadas posiciones críticas en torno al saber científico y tecnológico, en este trabajo utilizaremos la expresión "teoría crítica de la ciencia" como sinónimo de algunas de las premisas presentes en el análisis materialista histórico de la ciencia, que repasaremos a continuación. Al mismo tiempo, como se desarrolla en las conclusiones, nos proponemos articular estas premisas con otras dimensiones éticas y políticas.

Existen dos ejes nodales que consideramos necesario recuperar del análisis realizado por Marx en El Capital para pensar la actualidad de la ciencia y la tecnología, y su vinculación con problemáticas sociales. En primer lugar, la relación establecida entre ciencia, tecnología y capitalismo. En segunda instancia, la organización social de la ciencia y la tecnología que se deriva de esta articulación. En este análisis, fuerzas productivas son sinónimo de fuerzas productivas al capital. La innovación no se produce necesariamente allí donde existen necesidades sociales insatisfechas, sino donde la rentabilidad esperada es mayor. Herramienta de dominación, en tanto reproduce las condiciones sistémicas, el proceso innovador es contradictorio y socialmente costoso. Es en la época de la Gran Industria que Marx identifica que la ciencia y la tecnología, como prácticas humanas, quedan reducidas a su utilidad para la obtención de ganancias. En este movimiento, la técnica se deshumaniza.

Una vez imbricadas ciencia y tecnología, y articuladas en su imbricación al proceso de realización de mercancías, esta característica es válida para ambas. Esto no implica que todos los conocimientos científicos y tecnológicos sean generados con fines lucrativos, ni que en diferentes instancias pasadas y presentes efectivamente se articulen a transformaciones positivas de las condiciones colectivas de existencia. Implica que el sesgo mercantilizador posee un alcance hegemónico, que atenta contra la potencialidad de realización de la ciencia y la tecnología en tanto prácticas humanas. Es decir, contra su 
articulación con la vida misma. En este análisis, el carácter del cambio tecnológico posee tanto una dimensión coactiva (dada por su ligazón a la competencia), como indisociable del proceso de valorización. Así como el desarrollo de la fuerza productiva del trabajo no tiene por objeto reducir la duración de la jornada laboral, sino solamente el tiempo para producir cierta cantidad de mercancías, el cambio tecnológico tampoco apunta a la emancipación social. En este sentido, puede pensarse que la organización social de la ciencia es análoga a la organización social del trabajo.

Mientras que esta dinámica posee una vigencia palpable, tenerla presente requiere también atender las especificidades históricas y espaciales. Ciertamente, las formas de producción de conocimiento y los modos que ha asumido la mercantilización de la ciencia en nuestro presente no solamente no existían de este modo al momento de la escritura de El Capital, sino que, además, en lo relativo las ciencias de la vida en general y a la biotecnología en particular, también ha cambiado el modo en el que están incidiendo en nuestra existencia. Al mismo tiempo, junto a las transformaciones temporales, dentro de la dinámica global que atraviesa la producción científica y tecnológica también es necesario atender cómo su forma de desenvolvimiento en espacios geopolíticos diferentes conlleva problemáticas diversas.

Por otro lado, resulta fructífero pensar análogamente la descripción que realiza Marx cuando alude al pasaje producido entre el clásico movimiento que primero enfrentó trabajadores a maquinarias, para luego dar paso a una resistencia contra su forma social de explotación. Así, señala que "Se requirió tiempo y experiencia antes que el obrero distinguiera entre maquinaria y su empleo capitalista, aprendiendo así a transferir sus ataques, antes dirigidos contra el mismo material de producción, a la forma social de explotación de dicho medio" (Marx, [1867] 2003: 523). Por un lado, existen diferencias notables entre ambas esferas, entre ellas el hecho que la separación y oposición que se le presenta al asalariado con el producto de su propio trabajo no puede ser comparada en los mismos términos con lo sucedido entre los científicos contemporáneos y el producto de sus trabajos, en tanto se trata en múltiples ocasiones de científicos empresarios. Por otro, la comparación cabe para repensar el rol de la ciencia y las estrategias frente al combate de algunas de sus implicancias.

En otras palabras, si hoy la forma predominante de la ciencia y la tecnología responde a formatos empresariales, mercantilizadores y corporativistas, esto no implica que ésta sea su única capacidad de existencia, ni que las razones de su funcionamiento deban buscarse en algún rasgo intrínseco de esta práctica. Más bien, como en otros 
órdenes de la vida, son sus potencialidades de vincularse a la resolución de necesidades sociales las que vemos coartadas bajo este orden económico y social. No se trata de negar el carácter uniformador y colonizador que ha tenido la ciencia occidental por sobre otra gran cantidad de saberes, en su pretensión de autoerigirse como único conocimiento legítimo. Se trata de explicitar que este movimiento, como el de la pretendida neutralidad del cientificismo, encuentra su razón de ser en el nuevo interés cognitivo que bajo el capitalismo imbrica producción de conocimiento y obtención de ganancias. Si no haber vislumbrado aún un mundo que se rija por otras reglas en las que no exista una masa de desposeídos no inhibe el hecho que podamos (y debamos) apostar por su existencia, no estar en contacto con una ciencia que tenga otras finalidades, valores y potencialidades a las que necesariamente cumple en estas relaciones sociales de producción no debería quitarnos la expectativa de abogar por su transformación. Es, también, en sus intersticios en los que vale la pena bucear para encontrar y construir tendencias contra-hegemónicas.

Finalmente, en cuanto a la vinculación entre CyT y agricultura capitalista, vale la pena recuperar este pasaje. En él la descripción de Marx, si bien alude a un modo de explotación extensivo de la tierra coincidente con el momento en el que fuera escrito, contiene uno de sus rasgos definitorios hoy reinventado en el tiempo bajo nuevas formas:

"Al igual que en la industria urbana, la fuerza productiva acrecentada y la mayor movilización del trabajo en la agricultura moderna se obtienen devastando y extenuando la fuerza de trabajo misma. Y todo progreso de la agricultura capitalista no es solo un progreso en el arte de esquilmar al obrero, sino a la vez en el arte de esquilmar el suelo, todo avance en el acrecentamiento de la fertilidad de éste durante un lapso dado, un avance en el agotamiento de las fuentes duraderas de esa fertilidad. (...) La producción capitalista, por consiguiente, no desarrolla la técnica y la combinación del proceso de social producción sino socavando, al mismo tiempo, los dos materiales de toda riqueza: la tierra y el trabajador" (Marx, [1867] 2003: 613).

Esta definición, que contempla la simultánea explotación al obrero y al suelo, resuena en particular a la hora de pensar las actuales formas de explotación de la tierra en distintos países de América Latina, ligadas a la expansión de monocultivos, corrimientos de las fronteras agrícolas y uso intensivo de agrotóxicos. Para analizar la producción de conocimientos y la privatización de los comunes en estos territorios resulta imprescindible articular la indagación a los 
patrones productivos que, bajo sustanciales diferencias locales, delinean un mismo mapa de acumulación. El extractivismo, entendido como una forma específica de explotación y apropiación de la naturaleza, aparece en forma ineludible acompañado de relevantes implicaciones económicas, políticas y culturales. Según un informe del BID, hasta el 2003 América Latina concentraba el 23\% de la tierra cultivable, el $46 \%$ de los bosques naturales y el $31 \%$ del agua dulce del mundo (BID, 2003: 19, citado en Manzanal, 2012). Por su disponibilidad de recursos, fue, y continúa siendo, una tierra de oportunidades para la rentabilidad capitalista. En este marco, las semillas expresan de manera particular las contradicciones entre rentabilidad y derechos. Son la base de la soberanía alimentaria a escala planetaria $\mathrm{y}$, al mismo tiempo, el eje sobre el que se tejen negocios millonarios que incluyen a la producción semillera en sí, insumos agrícolas ligados vertical y horizontalmente a ésta, y cadenas de producción de conocimientos científicos y tecnológicos que dan como resultado cultivos modificados.

Mientras que su trasformación en mercancías se extiende, acompañada por un marco legal que en diferentes países de la región avanza imponiendo leyes que restringen el histórico derecho de los agricultores a resembrar e intercambiar semillas, también encontramos vivo el reclamo de las comunidades rurales y la pervivencia de otras definiciones que remarcan su importancia para el desarrollo de la vida. Algunas, incluso, dentro de las mismas instituciones que promueven los patrones productivos ya mencionados. Así, la Food and Agriculture Organization (FAO) de Naciones Unidas denomina "recursos fitogenéticos" a "todo material genético de origen vegetal de valor real o potencial para la alimentación y la agricultura" (FAO, 1996: 3). En la misma línea, el Instituto Nacional de Tecnología Agropecuario (INTA) argentino señala que "Los recursos fitogenéticos son mucho más que insumos básicos para los programas de mejoramiento de las especies cultivadas: son base de la alimentación de la humanidad" (INTA, 2009: 2). Sin embargo, acompañado por presiones internacionales, el escenario local muestra dinámicas de producción e investigación en las que priman los intereses corporativos de las grandes empresas. ¿Qué trayectorias históricas se expresan detrás de estas aparentes contradicciones? Analizar críticamente la construcción de los contenidos y beneficiarios de los programas de investigación en semillas puede permitirnos reflexionar en torno a las posibles implicancias de estas problemáticas en la construcción de un modelo agrícola alternativo, que priorice la concepción de las semillas y de los múltiples saberes asociados a ellas, como bienes comunes. 


\section{DE LA REVOLUCIÓN VERDE A HOY, TECNOLOGÍA AGRÍCOLA EN AMÉRICA LATINA: ¿SABERES COLONIZADOS?}

Durante milenios, la domesticación de plantas fue realizada en forma colectiva, generando un progresivo incremento de los rendimientos de la mano de múltiples procesos de cruza y selección. Desde los comienzos de la sedentarización y la agricultura hasta nuestros días, hace más de 10.000 años, la humanidad ha generado un caudal inconmensurable de conocimiento. Éste ha atravesado profundas transformaciones, en consonancia con los cambios que a lo largo de la historia se han producido en las relaciones sociales. Dentro de estas grandes etapas históricas, la aparición de la ingeniería genética, en el siglo $\mathrm{XX}$, marcó un antes y un después en la relación entre el hombre y la naturaleza, así como en los entramados entre ciencia y cultura, y en las relaciones entre ciencia y mercado (Palladino, 2002).

Entre 1943 y 1961, un programa de investigación agrícola y asistencia técnica desarrollado por los Estados Unidos fue puesto en marcha en México. Con él se originó el paquete tecnológico de la llamada revolución verde, que sería exportado a América Latina, Asia e India, con un profundo impacto tanto en los rendimientos de algunos de los principales cultivos, como en las distintas estructuras sociales agrarias. El Centro Internacional de Mejoramiento de Maíz y Trigo (CIMMyT) surgió como parte esta experiencia piloto radicada en México, con el patrocinio del gobierno mexicano y la Fundación Rockefeller. Bajo la dirección del científico Norman Borlaug, el CIMMyT desarrolló nuevas variedades de trigo (llamados "trigos enanos" por su altura) que respondían mejor a los fertilizantes que las variedades anteriores, crecían en diferentes latitudes, eran resistentes al vuelco por su enanismo, y a una enfermedad del trigo conocida como la roya del tallo (Gárgano, 2015).

Uno de los principales objetivos fue el desarrollo de redes de cooperación científica internacionales, que pusieran a prueba las nuevas variedades. Para la década de 1950, la Fundación Rockefeller invirtió en una campaña dirigida a exportar este modelo a países como India y Pakistán, cuya población superaba la producción de trigo y arroz, y hacia América Latina. En 1967, India importó 18.000 toneladas de semillas de las variedades de trigo mejoradas, y durante 1967-1971 los dos países duplicaron su producción triguera (CIMMyT, web). El término "revolución verde" fue utilizado por primera vez en 1968 por el ex director de la United States Agency for International Development (USAID), William Gaud, quien destacó que la difusión de las nuevas tecnologías "y otros desarrollos en el campo de la agricultura contienen los ingredientes de una nueva revolución. No es una violenta revolución roja como la de los soviéticos, ni es una revolución blanca 
como la del Sha de Irán. Yo la llamo la revolución verde”. Para 1970, Borlaug, el científico responsable del proyecto, considerado el padre de la revolución verde, fue galardonado con el Nobel de la Paz por su contribución en el combate del hambre en regiones de extrema pobreza mediante las nuevas variedades de trigo y arroz.

El argumento, central en los planteos de la revolución verde, establecía una conexión entre desfasaje de recursos y población, y soluciones tecnológicas que podían corregirlo. Sin embargo, la modernización tecnológica del agro tuvo como contrapartida la aparición de fuertes transformaciones sociales, económicas y ambientales. En este sentido, se ha señalado que los campesinos de menor escala no lograron adaptarse a los cambios y que las prácticas de extensión rural difundidas desde los Estados Unidos chocaron con los patrones culturales locales (Fitzgerald, 1986). Los programas iniciales fueron exitosos en las regiones mexicanas en las que las condiciones ambientales y socio-económicas eran similares a las del agro estadounidense. Así, mientras que la obtención y difusión de nuevos trigos fue exitosa, no ocurrió lo mismo con los maíces híbridos, compatibles con los farmers y con un agro capital intensivo como el estadounidense, pero no con la agricultura de subsistencia del campesinado mexicano (Fitzgerald, 1986). También se ha señalado que la "revolución verde" fue convergente a la movilidad de capitales -en ascenso luego de la caída de Bretton Woods- que fomentó el accionar de grandes firmas, empresas trasnacionales, laboratorios, semilleras y comercializadoras exportadoras, que pasaron a controlar la mayor parte del mercado agrícola internacional (Teubal, 2001). El modelo de investigación y extensión rural propagado desde entonces tuvo una gran impronta en la agricultura a nivel mundial. Su difusión implicó una transformación radical de la agricultura, dominada por la mecanización y la generación de semillas genéticamente modificadas de alto rendimiento, unidas a un paquete de fertilizantes, pesticidas y herbicidas. Cambios que estuvieron acompañados por la expansión a nivel mundial de la industria química, bioquímica y farmacológica.

A mediados de los años cincuenta resolver el problema de la descentralización de las actividades de investigación y extensión rural en organismos de administración autónoma fue clave para cumplir con los objetivos de la revolución verde. La creación de organismos públicos en distintos países periféricos considerados "en vías de desarrollo" fue simultánea, entre ellos el Instituto Nacional de Tecnología Agropecuaria (INTA) argentino (1956), el Instituto Nacional de Investigación Agropecuaria (INIA) de Ecuador (1959), el INIA de México (1960), el Instituto Colombiano Agropecuario (ICA) (1963), el INIA de Chile (1964) y otros similares. Este proceso fue acompañado 
por la puesta en marcha de organismos internacionales de investigación agropecuaria como el ya mencionado CIMMyT, el Centro Internacional de Agricultura Tropical (CIAT) en 1967, y el Centro Internacional de la Papa (CIP), en 1971, entre otros. Los nuevos organismos de investigación partieron de considerar la disponibilidad de la tecnología a nivel internacional para su adaptación y difusión a América Latina (Gárgano, 2018).

Esta centralidad de la cuestión científico y tecnológica, con predominio de esta última, y su incorporación a las agendas gubernamentales era en buena medida una herencia del escenario internacional configurado por la Segunda Guerra. Si bien, como señaláramos en un inicio retomando el análisis de Marx, la imbricación entre la práctica científica y la tecnológica, y su sentido, puede rastrearse en los comienzos Gran Industria, en este período adquiere una nueva configuración, que profundiza esta dimensión. No solamente por el peso dado a la CyT en las actividades de defensa y sus correspondientes partidas presupuestarias, también por la gestación de proyectos tecnológicos a gran escala como asuntos de Estado. En este sentido, el énfasis de la doctrina Truman -presidente de los Estados Unidos entre 1945 y 1953- en los beneficios de CyT para de áreas subdesarrolladas también fue fundamental para la concepción de un modelo de desarrollo rural, y su exportación (Manzanal, 2012). En plena Guerra Fría, en 1961, esta incidencia se manifestaría en el encuentro en Punta del Este, Uruguay, del Consejo Interamericano Económico y Social, al que asistieron representantes de todos los países miembros de la OEA (incluido Ernesto Che Guevara, por Cuba), en donde el desarrollo rural copó buena parte de la agenda (Fagueinbaum Chame, 2001: 25). De esta reunión surgía la Alianza para el Progreso.

Junto a la asistencia técnica, el financiamiento emanado de organismos internacionales fue de gran peso en esta etapa, en un marco internacional signado por la amenaza de la reproducción de la revolución cubana (1959). Las agencias de la ONU tuvieron un rol destacado en la configuración de los programas de "desarrollo rural", en especial la Comisión Económica para América Latina (CEPAL), la FAO, el Instituto Latinoamericano de Planificación Económica y Social (ILPES) y el Banco Mundial (BM). También lo tuvieron las Fundaciones, en particular la Fundación Rockefeller, los organismos de las agencias bilaterales para el desarrollo, como la Agencia Internacional para el Desarrollo (AID), el Banco Interamericano de Desarrollo (BID) y la Secretaría General de la OEA. Las agencias internacionales (OEA, BID, CEPAL, FAO) conformaron el Comité Interamericano de Desarrollo Agrícola (CIDA), en cuyos objetivos puede leerse claramente cómo la disputa política internacional 
forzaba un lenguaje que décadas después sería visto como radicalizado, llegando incluso a desaparecer por completo de las prioridades gubernamentales en materia de desarrollo rural. Así, por ejemplo, el CIDA afirmaba que su meta era "transformar las estructuras e injustos sistemas de tenencia y explotación de la tierra" (Faiguenbaum Chame, 2005: 26). El discurso en torno al agro estaba teñido por los altos niveles de conflictividad social del agro latinoamericano, y por el temor a una propagación de experiencias socialistas con posterioridad a 1959. Por fuera de las retóricas, el andamiaje teórico que sustentó tanto las visiones del desarrollo como las agendas de la extensión rural (ideada para el contacto directo con los productores), estuvo protagonizado por los principales exponentes de la sociología rural norteamericana en el marco de la revolución verde. Difundido en América Latina por organismos internacionales como el Instituto Interamericano de Cooperación para la Agricultura (IICA) y hegemonizado por los teóricos de la "modernización agraria" encabezados por Everett Rogers (Alemany y Sevilla Guzmán, 2007: 56), este enfoque puso énfasis en barrer "resistencias culturales" de la población rural de la periferia identificadas con el atraso. Una de las principales críticas posteriores al resultado de la difusión de este modelo es que redundó en una extensión agrícola asistencialista, unida a la necesidad de evitar los desbordes sociales mediante una integración subordinada de las franjas de agricultores de menores recursos (Gárgano, 2017).

Durante la década de 1960, los patrones de la revolución verde se fueron expandiendo, asociando el uso de semillas mejoradas a la utilización de herbicidas y nuevas técnicas de irrigación. Junto a la creación de organismos públicos de investigación y extensión rural, este proceso fue acompañado por transformaciones en la legislación relativa a las semillas. En 1961 fue creada la Unión para la Protección de Variedades Vegetales (UPOV). Firmada originalmente por seis naciones europeas, en sus futuras modificaciones (1972, 1978 y 1991) iría incorporando más adherentes. La regulación de la propiedad intelectual referida a la obtención de nuevas semillas primero avanzó mediante los derechos de obtentor, en las décadas subsiguientes lo haría mediante las patentes de invención, que ampliarían su alcance a sucesivas generaciones de la variedad obtenida. Como veremos, este punto colisionaría con el derecho a resembrar de los agricultores.

En Argentina, la creación del INTA en 1956 fue una expresión del escenario internacional configurado por la revolución verde, y a la vez supuso un alcance inédito de la agencia estatal en el ámbito rural a través de la diseminación de una red de Agencias de Extensión Rural y Estaciones Experimentales Agronómicas a lo largo del país, que posibilitaron la ampliación de la cobertura territorial. Primer organismo 
dedicado oficialmente a la investigación y extensión rural en el país y en toda América Latina, fue creado como organismo autárquico, con capacidad de intervención en todo el territorio nacional. Mientras que a nivel internacional, tanto el CIMMyT como las universidades extranjeras y, en menor medida, las estaciones experimentales agronómicas de los Estados Unidos, abastecieron de material genético a las empresas transnacionales y locales (Rasmussen, 1989), en Argentina, el INTA fue el principal organismo que proveyó de material genético a la industria semillera. Dentro de sus planes de investigación, la adaptación y obtención de semillas mejoradas ocupó un lugar central, con la genética como matriz disciplinar y la experimentación en campo como práctica central dentro de sus distintas estaciones experimentales agronómicas.

El organismo poseía el mayor campo experimental de trigo de toda Sudamérica, situado en su estación experimental Marcos Juárez, en la provincia de Córdoba. El mismo Norman Borlaug propuso la creación de un programa de cooperación científico-técnica entre el CIMMyT, el INTA y la Fundación Ford, que se concretó en 1961. A través de esta articulación, el INTA introdujo los llamados "trigos mexicanos", las líneas Norin 10 x Brevor y sus derivados, desarrollando nuevos trigos sobre la base de cruzamientos entre variedades mexicanas y argentinas. En maíz, incursionó tempranamente en la obtención de híbridos, y fue pionero en la realización de investigaciones para la adaptación y difusión de la soja, en un momento en el que aún el cultivo no contaba con la rentabilidad que alcanzaría en los años subsiguientes (Gárgano, 2015). Encabezadas por trigo, el rol del INTA fue relevante sobre todo en especies autógamas de cereales y oleaginosas. ¿A qué respondía esta situación? En buena medida, porque este tipo especie implica la ausencia de atractivos comerciales en la fase de generación de las variedades. A diferencia de las alógamas (como el maíz), en las especies autógamas (como el trigo y la soja), el agricultor puede hacer su propia semilla, ya que la semilla que dio origen a la planta y el grano cosechado contienen la misma información genética (Gutiérrez, 1986: 3). Esto implica que una nueva creación de una especia autógama es fácilmente reproducible. En cambio, en el caso de las alógamas, el grano cosechado no puede ser usado como simiente, lo que obliga al agricultor a comprar semilla todos los años. De otro modo, los rendimientos decrecen paulatinamente. Por esta razón, las variedades autógamas no interesaban a las empresas semilleras (Alapin, 2008: 30) y fue el INTA quien ocupó este nicho. Esta situación no impidió que los capitales privados accedieran a los beneficios directos de la introducción de los trigos mexicanos y a los indirectos, derivados de la utilización del ciclo corto de los nuevos trigos para su rotación con soja, que pronto apuntalarían la expansión de ésta. 
Durante la década de 1960, en el momento de conformación de la industria semillera local, una disposición de la Secretaría y Agricultura de la Nación estableció en 1959 el secreto comercial de los híbridos del sector privado (el llamado "pedigree cerrado"), mientras que obligó a que los híbridos del sector público mantuvieran disponible la información de sus fórmulas ("pedigree abierto"), sin percepción de regalías, generando que los híbridos de la naciente industria semillera fueran registrados como propios a partir de las investigaciones realizadas en el sector oficial. El sector privado fue creciendo utilizando las líneas desarrolladas con fondos públicos, de libre disponibilidad, mientras que los híbridos oficiales disminuyeron. ${ }^{1}$ En la década siguiente, esta tendencia se profundizaría.

Si bien desde la propia creación de los organismos los planes de investigación respondieron al marco internacional de la revolución verde, la realidad local impuso sus propias condiciones. Así, mientras que se intentó extrapolar modelos institucionales, prácticas de investigación y estrategias de contacto con la población rural, tomando como referente organizacional al INRA francés y al sistema de extensión rural estadounidense, la propia configuración de las necesidades del agro argentino, sus profundas variantes geográficas y el convulsionado mapa social y económico del país también impusieron su agenda, dando como resultado experiencias diversas. Los contenidos de las agendas de investigación y extensión rural no permanecieron al margen de estas tensiones y se convirtieron ellas mismas en terrenos en disputa. En un contexto político signado por la interrupción del orden democrático (1976-1983), fueron relegadas las orientaciones que habían comenzado a cuestionar el formato verticalista y culturalista de la extensión rural impulsada por los teóricos de la modernización agrícola. Las herramientas teóricas provenientes de la educación popular y la investigación participativa, que habían comenzado a surgir más por iniciativa de algunos extensionistas que por directrices institucionales, fueron descartadas, al tiempo que se reducían las actividades de tipo sociocultural dirigidas a jóvenes y mujeres, reforzando el contacto con productores capitalizados y retomando la idea -heredada de las décadas de 1950 y 1960- de la necesidad de cambiar la mentalidad del productor (Gárgano, 2017). Si en un comienzo este

1 Dentro de este proceso, cabe destacar la migración o contratación temporaria de técnicos y científicos provenientes de organismos públicos de investigación. Por ejemplo, la empresa Cargill, pionera en híbridos de maíz, en Argentina comienzó a trabajar en base a los materiales públicos del Instituto Ángel Gallardo, contratado a uno de los principales responsables de la creación de los híbridos oficiales (Gutiérrez, 1986: 28). 
enfoque estuvo asociado a la difusión de las nuevas técnicas, en este período se inscribió plenamente en la lógica mercantil y en la reconfiguración de un espacio rural signado por la concentración de capital y la polarización social. Como argumentación, conservó, al menos en un plano retórico, una justificación cercana al determinismo tecnológico, que asociaba linealmente mayor difusión tecnológica, mejores rendimientos, y elevación del nivel de vida de la población. Al mismo tiempo, la intervención militar del INTA dispuso en 1979, a través de una resolución, la cesión de sus recursos fitogenéticos a los criaderos privados (Gárgano, 2015). Entre 1976 y 1986 el INTA no inscribió ningún híbrido, si bien se ha estimado que dos líneas oficiales permanecieron presentes en el $80 \%$ de los cultivares (Katz y Bercovich, 1988). Posteriormente, su posición no volvió a ser significativa. En simultáneo, la orientación económica aperturista impactó en el agro con una fuerte concentración de capital protagonizada por empresas transnacionales semilleras y agroquímicas.

La Ley 20.247 de Semillas y Creaciones Fitogenéticas, sancionada en 1973 y puesta en práctica dese 1978, introdujo el concepto de protección de la propiedad de las creaciones fitogenéticas, es decir el derecho del obtentor. Como señalamos, el debate internacional sobre la protección de la propiedad intelectual para variedades vegetales se había instalado desde fines de 1950, con los primeros acuerdos internacionales que legislaron sobre los derechos de fitomejoradores. En 1978 Argentina adhirió a la UPOV. Dos exenciones fueron incorporadas en esta instancia: la del obtentor (que permitía intercambiar materiales con fines de investigación) y la del agricultor (que garantizaba el histórico uso propio de los agricultores para reservar y utilizar semillas). Sin embargo, este marco regulatorio incrementó la protección hacia los derechos de los obtentores del sector privado, los únicos capaces de registrar y restringir sus creaciones. Esta situación fue más visible en el caso del maíz, por el interés comercial asociado a los híbridos.

Mientras que, a lo largo de la década de 1960, las investigaciones oficiales habían apuntalado la consolidación de la industria semillera local (sin ningún tipo de retorno por la utilización de las investigaciones), durante la década de 1980 los conocimientos generados se articularon tanto a la situación de crisis local como a un nuevo escenario transnacional. El fin de los años ochenta, en plena crisis inflacionaria, vio nacer los "Convenios de Vinculación Tecnológica" (CVT) con empresas. El pionero fue precisamente el INTA, en 1987. Mediante estos convenios el Estado estableció acuerdos con el sector privado, que a cambio de financiar parte de las investigaciones accedió en forma explícita a la utilización comercial de los resultados. Poco después, 
estos "desarrollos conjuntos" le sirvieron al INTA para garantizar su supervivencia durante el brutal recorte al presupuesto que enfrentó en la neoliberal década de 1990, y formalizaron una relación que en los hechos ya estaba desplegándose.

Estas características de la producción tecno-científica argentina dialogaron también con tendencias internacionales, donde la orientación que primó fue el avance hacia la privatización de la ciencia y la tecnología (Pestre, 2005). El gran salto fue dado en la década de 1980, en los Estados Unidos, a partir de la autorización legal del patentamiento de organismos vivos. Dos relevantes transformaciones del marco regulatorio de la actividad científica se vincularon a esta problemática: el Acta de Transferencia de Tecnología de StevensonWydler, que facilitó los convenios entre laboratorios públicos, universidades y empresas, y la Enmienda Bayh-Dole a las leyes de patentes, que otorgó a las universidades y centros de investigación la posibilidad de percibir derechos de propiedad intelectual por trabajos realizados con fondos públicos (Krimsky, 1991). En paralelo, los avances biotecnológicos se dispararon y, de la mano de la técnica de la transgénesis, se alteraron las fronteras naturales al tiempo que se trastocaba la estructura social agraria en múltiples latitudes mediante diversos procesos de agriculturización basados en la extensión de la frontera agrícola a zonas antes marginales, usualmente de la mano de la expansión de un monocultivo. ${ }^{2}$ Estas nuevas semillas comenzaron a ser comercializadas junto a nuevas técnicas de siembra (la siembra directa) y a los agroquímicos a los que la manipulación genética las vuelve resistentes. ${ }^{3}$ La concentración e integración de la industria semillera y de la química alcanzó nuevos umbrales, sin que se garantizara la vigencia del principio precautorio de daños potenciales (Leff, 2005), daños hoy hechos realidad. La Organización Mundial de la Propiedad Intelectual (OMPI), creada en 1967, pasó a regular las UPOV. Y, precisamente en este nuevo contexto, fue realizada la transformación UPOV 1991 que recortó las exenciones que la normativa anterior daba a fitomejoradores y a agricultores.

En la actualidad, en Argentina los CVT continúan siendo fundamentales dentro de la política de vinculación tecnológica del INTA, la organización de sus agendas y de sus recursos. Dentro de ellos, los

2 La transgénesis implica la transferencia de un gen de un organismo a otro organismo receptor (llamado transgénico) que habitualmente puede transferirlo a su descendencia. Nos referimos en este trabajo únicamente a la transgénesis vegetal.

3 El caso paradigmático ha sido el de la soja resistente al herbicida glifosato, comerciado comercialmente bajo el nombre de Roundup Ready por la firma Monsanto, hoy fusionada con Bayer. 
referidos a fitomejoramiento ocupan un lugar sumamente destacado. De hecho, el Convenio que reporta mayores regalías al organismo y que es considerado por directivos y científicos como modelo exitoso, refiere a la obtención de variedades modificadas de arroz, en convenio con la firma multinacional de origen alemán BASF. Lo llamativo e ilustrador de este caso no solamente refiere a las profundas asimetrías con relación a la participación en las ganancias derivadas de las investigaciones, ya que la explotación comercial es cedida a BASF en todo el mundo, con excepción de Argentina y Uruguay. Más relevante aún resulta observar por qué fueron generadas las investigaciones y cómo han configurado un paquete tecnológico cerrado que, a medida que se expande, configura nuevas dependencias hacia el uso de insumos. Las variedades fueron desarrolladas a partir de identificar el potencial interés de la empresa, productora de un herbicida del grupo de las imidazolinas conocido como sistema Clearfield [campo limpio], en una variedad de arroz resistente a este mismo herbicida. Es decir, BASF había desarrollado un herbicida capaz de controlar una maleza (el "arroz colorado"), y el INTA argentino se dispuso a idear una variedad que fuera inmune a ese mismo herbicida, para luego ofrecer un CVT a la firma. Como explica el investigador responsable del equipo que obtuvo las variedades, la maleza en cuestión "es un arroz como cualquiera, nada más tiene el pericarpio rojo" (Livore, 2017, entrevista). Es decir, es un arroz que no tiene un déficit nutricional, ni componente tóxico alguno, simplemente su aspecto lo vuelve poco rentable en la mayoría de los países compradores, en los que se busca un grano blanco. Cómo y por qué es concebido el objeto de estudio, en este caso por qué una variedad de arroz es identificada como una maleza, se construye en función de su utilidad comercial.

En relación con los riesgos implicados y la consideración de principios precautorios, la técnica utilizada, mutagénesis, permite saltear las regulaciones y trabas comerciales (donde existen) que actualmente recaen sobre los cultivos transgénicos. La mutagénesis es utilizada desde mediados del siglo XX, consiste en inducir mutaciones en el genoma por medio del uso de sustancias químicas o radiaciones que generan cambios en la planta. Al no implicar la incorporación de un gen extraño, proveniente de otro organismo, no existe una regulación específica como en el caso de los transgénicos. Según el Consejo Argentino para la Información y el Desarrollo de la Biotecnología (ARGENBIO), creado con el fin de divulgar información sobre la biotecnología, la técnica elegida por los investigadores del INTA (mutagénesis inducida) figura entre las "convencionales", aunque en este caso las mutaciones no son hechas al azar como en décadas anteriores, sino guiadas desde el laboratorio con marcadores moleculares. Según 
reseña ARGENBIO la biotecnología acelera este proceso siendo "una herramienta más segura y eficiente para el mejoramiento de especies" (ARGENBIO, web). Se trata de un relato que podemos calificar de continuista, en tanto genera una narración sin fisuras que comienza con la sedentarización y las primeras prácticas agrícolas y llega hasta nuestros días con las herramientas biotecnológicas. Cabe mencionar que los miembros fundadores de ARGENBIO son BASF, Bayer, Bioceres, Dow AgroSciences Argentina, Monsanto Argentina, Nidera, Pioneer Argentina y Syngenta. Al igual que en el discurso del investigador del INTA, "precisión" y "rapidez" son dos de las ideas clave. Sin embargo, la presión selectiva aplicada para obtener la variedad mutagénica genera también nuevas resistencias no buscadas originalmente. Lejos de ser un problema, esta situación deviene en la obtención de nuevas variedades resistentes a un nuevo grupo de herbicidas, configurando así nuevos paquetes tecnológicos (Gárgano, 2018). Esto supone una creciente dependencia de los agricultores al mercado y la generación de potenciales desequilibrios ambientales que no pueden ser considerados en un comienzo, dado que no existe un control sobre las mutaciones realizadas por fuera de la búsqueda inicial. El resultado es una cadena comercial virtuosa que, como reverso, es igualmente viciosa social y ambientalmente. ${ }^{4}$

Sheldon Krimsky (1991) ha caracterizado como "capitalismo académico" a los patrones de producción de conocimiento que proliferaron como consecuencia de la imbricación creciente entre universidades y empresas. En Argentina, esta problemática es indivisible de su matriz de productiva, por lo que los conocimientos vinculados a la producción agrícola juegan un rol primordial. Y, ciertamente, la definición excede al ámbito universitario. En prácticamente la totalidad de los convenios de vinculación tecnológica vigentes entre el INTA y empresas privadas el beneficio institucional redunda en el reconocimiento internacional de la genética desarrollada por el organismo, y en la obtención de regalías (magras en comparación con las ganancias millonarias derivadas de la comercialización de las variedades a nivel mundial), para seguir trabajando en los programas de mejoramiento. La vigencia de esta tendencia a la apropiación privada de los resultados de las investigaciones en semillas realizadas con fondos públicos actualmente se articula también al crecimiento del agronegocio a nivel local y a la concentración mundial de la actividad. El 65,4\% de la producción mundial de agroquímicos permanece actualmente concentrada en tres empresas, ChemChina-Syngenta $(25,8 \%)$, Bayer-Monsanto $(24,6 \%)$ y

4 Para un análisis ampliado de este caso, véase Gárgano (2018). 
DuPont-Dow (15\%). En el área de semillas, el 60,7 \% del mercado queda a cargo de las mismas firmas: Bayer-Monsanto $(30,1 \%)$, DuPont-Dow $(22,7)$ y ChemChina-Syngenta $(7,9 \%)$ (Ribeiro, 2015). En este marco de progresiva concentración horizontal y vertical, se multiplica la utilización de germoplasma proveniente del sur. En simultáneo, en países como Argentina, Colombia, Ecuador, Paraguay, México y Brasil se impulsaron e impulsan leyes para modificar las legislaciones nacionales en materia de semillas que amenazan con poner fin a las exenciones a los agricultores, el histórico "uso propio".

Los esquemas de extractivistas de acumulación presentes en Argentina y en buena parte de la región, sostenidos en base a vinculaciones entre los poderes financieros transnacionales y los gobiernos locales, han dado como resultado un patrón concentrador y excluyente con altos costos sociales y ambientales (Manzanal, 2012). Éste, caracterizado por Svampa (2013) como el "consenso de las commodities", opera en buena medida bajo la expansión de la acumulación por desposesión. Bajo esta denominación Harvey (2005) alude a la reactualización de prácticas depredadoras de acumulación primitiva u originaria, que habrían crecido aún más que la reproducción ampliada del capital, operando mediante diversos mecanismos que mercantilizan ámbitos o recursos que permanecían sin enajenar, como los bienes naturales comunes (agua, semillas, energía). Algunos de estos mecanismos son de larga data y otros, como los derechos de propiedad intelectual, de más reciente aparición. En este sentido, puede pensarse que también la dimensión cognitiva, en particular la producción de conocimiento científico y tecnológico, juega un rol singular en este esquema. La transformación de bienes comunes naturales en commodities agrícolas se realiza dando un lugar primordial al carácter conocimiento intensivo de estas mercancías agrarias. Qué y para qué investigar no solamente queda relegado a esta dinámica de acumulación, al mismo tiempo, estas investigaciones la sostienen. Así, la acumulación por desposesión incluye también a la producción local de conocimiento. Y, fuera del sentido general, donde efectivamente se pierden capacidades de decisiones autónomas y se relega (se despoja) la posibilidad de producir ciencia en línea a necesidades colectivas locales, en rigor se trata una cesión legalmente regulada y dirigida por un Estado de carácter empresarial.

\section{CONCLUSIONES (O CIENCIA PARA QUÉ Y PARA QUIÉNES)}

Las tensiones existentes entre la conceptualización de las semillas como bienes comunes, pilares en la reproducción de la humanidad, y su transformación en mercancías, operan dentro de un proceso histórico. En éste, la mercantilización del conocimiento científico asociado 
a la obtención de nuevas variedades posee relevantes derivaciones. En Argentina, esta trayectoria de apropiación privada de conocimientos tuvo diferentes hitos, que dialogaron con trasformaciones de alcance internacional. Actualmente, en un agro en el que la PEA agrícola ha disminuido del 42\% en 1970 al 24\% en 2000 (Manzanal, 2012), cuando los mismos organismos que financiaron Programas de Desarrollo rural en toda América Latina señalan su preocupación por los niveles de pobreza del agro, cabe preguntarnos: ¿es ésta la única posibilidad de direccionamiento (y por lo tanto de apropiación) del conocimiento científico y tecnológico? ¿Cuánta utilidad les reportan a la población rural los convenios de vinculación con firmas transnacionales, que generan semillas genéticamente modificadas para ser resistentes a los herbicidas que estas mismas empresas producen? La ecuación resulta inviable mientras las comunidades rurales no sean incorporadas al esquema, binario y al mismo tiempo en permanente retroalimentación, "público-privado". Denominación falaz que esconde que ni "estatal" es sinónimo de "público", ni el Estado juega un rol pasivo en el proceso de despojo, ni existe un margen para la discusión colectiva de las prioridades de agendas y recursos de investigación. Y eso sin mencionar que el Estado argentino tampoco recauda fondos derivados de las investigaciones agrícolas que promueve para incorporarlos al gasto público en general, y a los agricultores en particular.

Al mismo tiempo, si el Estado, además de garante de un orden social, es considerado como una arena en disputa (De Sousa Santos, 2006), el ámbito de producción científica no debería ser dejado fuera de la agenda de preocupaciones a la hora de discutir una agricultura alternativa a los actuales modelos de explotación del suelo y expulsión de los pobladores del campo. Por un lado, por el peso de los patrones culturales, económicos y políticos que han atravesado los programas de investigación en fitomejoramiento impulsados en América Latina desde la revolución verde. Por otro, porque el direccionamiento y construcción de las agendas de investigación y extensión rural es también un terreno en disputa. Así, dentro de una misma institución como el INTA argentino, existen agendas, proyectos y orientaciones en tensión. En ella conviven planes de trabajo con comunidades campesinas en regiones como el noroeste y el noreste, investigaciones orientadas a la agricultura familiar, tareas de extensión rural con inserción territorial que cuestionan las concepciones heredadas de los antiguos teóricos de la modernización agrícola, con investigaciones de sesgo "productivista" y programas, en particular en semillas, que parecen diseñados a demanda de los requerimientos de las grandes firmas transnacionales productoras de insumos agrícolas. Ciertamente, la convivencia no se desarrolla con simetría de fuerzas ni recursos, y el carácter estatal de 
estos ámbitos opera como un límite a estas iniciativas. Sin embargo, por su grado de alcance y repercusión, y por el modo en el que estos conocimientos forman parte de los esquemas productivos vigentes, repensar las formas de vida en el ámbito rural también requiere discutir ciencia para qué y para quiénes, y operar los intersticios de estos espacios.

Como señalamos, en tanto construcción colectiva, tanto el proceso social de creación de conocimiento como su potencialidad se rompen cuando se subordinan a la lógica sustentada en la búsqueda de ganancia. En particular, la actual forma de organización de la producción de conocimiento científico y tecnológico en América Latina se encuentra atravesada por la configuración de sus matrices productivas. En este escenario, es necesario ubicar a la dimensión cognitiva como parte constitutiva de los modelos extractivistas y de las relaciones neocoloniales que los constituyen. La extracción creciente de bienes comunes naturales está siendo acompañada cada vez más por la fuga de resultados de investigación. Más específicamente, de las ganancias derivadas de estos resultados. Este proceso expone y contiene dos implicancias fundamentales. Por un lado, la existencia de alianzas entre comunidades de investigación y empresas transnacionales (Dagnino, 2009) que indica que es el Estado quien financia las rentas privadas. Por otro, que las prioridades de las agendas se definan en función del lucro potencial derivado de su articulación a la producción agrícola transnacional, y lejos de las necesidades (colectivas) locales. En este sentido, como señalamos, es posible pensar que la acumulación por desposesión (Harvey, 2005) incluye también a la producción local de conocimiento. Y al mismo tiempo, cabría revisar la categoría de "desposesión" ya que lo que encontramos es una cesión. La apropiación privada de conocimientos científicos, en las que el Estado, su principal productor, lejos de jugar un rol pasivo y de meramente expoliado, es un eslabón clave para la consecución de la transferencia y utilización de los conocimientos con fines lucrativos que poco tienen que ver con el incremento de la calidad de vida de la sociedad que financia las investigaciones.

Finalmente, resulta oportuno recuperar algunas de las reflexiones de Iván Illich en torno a la producción tecnológica y al rol de los profesionales, para recuperarlas en función de los problemas del espacio rural. Por un lado, cómo una determinada noción de progreso tecnológico fomenta "la parálisis de la producción de valores de uso" (Illich, 1981: 30). Es decir, que la nueva tecnología no esté siendo "incorporada al equipamiento convivencial" sino generando una "riqueza empobrecedora". Por otro, cómo el rol de los expertos (científicos y tecnólogos) monopoliza las discusiones en torno a sus implicancias, 
y a la vez traduce otros conocimientos. En este marco, aboga por un control lego sobre la tecnocracia, una construcción comunitaria de un perfil tecnológico que cuestione cómo queremos vivir. Democratizar las dimensiones tecnológicas en este enfoque está imbricado a un control social de la producción (Illich, 1981). Si este planteo es pertinente para el conjunto de las actividades científicas y tecnológicas, su vigencia para aquellas que afectan a la producción agrícola, y en especial a la de semillas, es clave, en tanto se trata de una práctica que se vincula directamente a las condiciones de existencia y reproducción de las comunidades. Al mismo tiempo, por el modo en el que los profesionales de esta área han operado minimizando riesgos potenciales y priorizando la búsqueda de regalías y el afianzamiento de convenios, con el argumento de que su tarea logra conectar la actividad científica a necesidades concretas del sector productivo, gracias a su impacto directo en el incremento de los rendimientos agrícolas. Esta argumentación expresa cómo las lógicas de las instituciones científicas y de desarrollo tecnológico operan encarnado intereses económicos y políticos concretos.

Como se ha analizado, las trayectorias históricas de los organismos de investigación implicados en la producción agrícola desde la revolución verde a la actualidad han jugado un rol fundamental en configurar las agendas de investigación e impulsar modelos de producción de semillas. Explicitar qué tipo de utilidad (mercantil) del conocimiento se impulsa, tener en claro su fundamento histórico y su razón de ser en este orden social resulta tan importante para plantear escenarios alternativos, como reconocer que en múltiples espacios (mediáticos y profesionales) este sentido continúa siendo presentando como natural y neutral. Si bien todos los componentes (elementos regulatorios y jurídicos, contenidos epistémicos, mecanismos y procedimientos tecnológicos, articulaciones internacionales) que hacen a la densa trama que constituye a la producción de conocimiento científico y tecnológico implicado en la obtención de semillas tienen un grado de especificidad y complejidad evidente, su incidencia en nuestros cotidianos es tan alta que no puede dejarse librado a un selecto (y partícipe) grupo.

Recuperar el carácter común del conocimiento (y de las semillas) es, finalmente, parte de una misma disputa. La batalla por un modo distinto de pensar, producir y vivir.

\section{BIBLIOGRAFÍA}

Alapin, H. 2008 Rastrojos y algo más. Historia de la siembra directa en Argentina (Buenos Aires: Teseo).

Alemany, C. y Sevilla Guzmán, E. 2007 “¿Vuelve la extensión rural?: 
Reflexiones y propuestas agroecológicas vinculadas al retorno y fortalecimiento de la extensión rural en Latinoamérica", Realidad Económica, 227, pp. 52-74.

Bartra, A. 2006 El Capital en su laberinto. De la renta de la tierra a la renta de la vida (México DF: Universidad Nacional Autónoma de México).

Bollier, D. 2008 "Los bienes comunes: un sector soslayado de la creación de riqueza". En Helfrich, S. (comp.). Genes, bytes y emisiones: bienes comunes y ciudadanía (México DF: Ediciones Böll) pp. 30-41.

Boyle, J. 2003 The second enclosoure movement and the construction of the public domain. Disponible en: https://scholarship.law.duke. $\mathrm{edu} / \mathrm{cgi} /$ viewcontent.cgi? article $=1273 \&$ context $=\mathrm{lcp}$

Dagnino, R. 2009 "A construção do Espaço Ibero-americano do Conhecimento, os estudos sobre ciência, tecnologia e sociedade e a política científica e tecnológica" en Revista CTS, (4) 12, pp. 93-114.

De Sousa Santos, B. 2006 Reinventar la democracia. Reinventar el Estado (Buenos Aires: CLACSO).

Díaz Rönner, L. 2013 "Biotecnología y propiedad intellectual” en Martínez Dougnac, G. (comp.) De especie exótica a monocultivo. Estudios sobre la expansión de la soja en Argentina (Buenos Aires: Imago Mundi), pp. 65-115.

Faiguenbaum Chame, S. 2011 ¿Ciencia o política pública? Cuatro décadas de investigación agropecuaria del INIA (Santiago de Chile: Consejo Nacional de la Cultura y las Artes).

FAO - Dirección de Producción y Sanidad Vegetal 1996 Informe sobre el estado de los recursos fitogenéticos en el mundo, Conferencia Técnica Internacional sobre los Recursos Fitogenéticos (Leipzig: FAO).

Fitzgerald, D. 1986 "Exporting American Agriculture" en Social Studies of Science, 16, 457-483, https://www.jstor.org/ stable/285027

Gárgano, C. 2015 Semillas, ciencia y propiedad. Una mirada al ciclo de producción de conocimiento en el INTA de Argentina. REDES, 39, pp.15-36.

Gárgano, C. 2017 "Rupturas y continuidades en el perfil de la extensión rural argentina” en Quinto Sol, 21 (2), DOI: http:// dx.doi.org/10.19137/qs.v21i2.999

Gárgano, C. 2018 "Ciencia, Tecnología y Mercado: Investigaciones en Arroz en el INTA argentino" en Journal of Technology Management \& Innovation, 13 (1), pp. 75-83, http://www.jotmi. org/index.php/GT/article/view/2425 
Gutiérrez, M. 1986 Semillas mejoradas: Tendencias y rol del sector público (Buenos Aires, Centro de Investigaciones Sociales sobre el Estado y la Administración).

Harvey, D. 2005 El "nuevo imperialismo": acumulación por desposesión. (Buenos Aires: CLACSO) Disponible en http:// biblioteca.clacso.edu.ar/clacso/se/20130702120830/harvey.pdf

Helfrich, S. y Hass, J. 2008 "Genes, bytes y emisiones: acerca del significado estratégico del debate de los bienes comunes" en Helfrich, S. (comp.) Genes, bytes y emisiones: bienes comunes y ciudadanía (México: Ediciones Boll), pp. 311-328.

Illich, I. 1981 "Profesiones inhabilitantes" en Illich, Iván, Zola, Irving, Mc Knight, J., Caplan, J. y Shaicken, Harley Profesiones inhabilitantes (Madrid: H. Blume).

Krimsky, S. 1991 "The profit of scientific discovery and its normative Implications”, Chicago Kent Law Review, 75 (3), pp. 15-39.

Leff, E. 2005 “La Geopolítica de la Biodiversidad y el Desarrollo Sustentable: economización del mundo, racionalidad ambiental y reapropiación social de la naturaleza". En: Semináro Internacional REG GEN: Alternativas Globalização (8 al 13 de Octubre de 2005, Rio de Janeiro, Brasil) UNESCO, Organización de las Naciones Unidas para la Educación, la Ciencia y la Cultura. Disponible en: http://bibliotecavirtual.clacso.org.ar/ar/ libros/reggen/pp12.pdf

Livore, A. 2015 Entrevista a director del Programa de Mejoramiento de arroz, Estación Experimental Agronómica Concepción del Uruguay del INTA (Concepción del Uruguay, Entre Ríos) 12/12/2017; 04-07, 2015

Manzanal, M. 2012 "Poder y desarrollo. Dilemas y desafíos frente a un futuro ¿cada vez más desigual?”, en Manzanal, M. y Ponce, M. (org.) La desigualdad ¿del desarrollo? Controversias $y$ disyuntivas del desarrollo rural en el norte argentino (Buenos Ares: Ciccus), pp. 17-49.

Marx, K. 2003 (1867) El capital, Tomo I, Vol. II, "El proceso de producción del capital" (Buenos Aires: Siglo XXI).

Moulier Boutang, Y. 2002 "Nouvelles frontières de l'économie politique du capitalisme cognitif", Disponible en www.ish-lyon. cnrs.fr/labo/walras/Objets/New/20021214/YMB.pdf

Nuñez Jover, J. 2001 "Ciencia y cultura en el cambio de siglo. A propósito de C.P. Snow" en López Cerezo, J. A. y Sánchez Ron, J. A. (eds.) Ciencia, Tecnología, Sociedad y Cultura en el cambio de siglo (Madrid: Biblioteca Nueva), pp. 89-107.

Palladino, P. 2002 Plants, Patients and the Historian: (Re)membering in the Age of Genetic Engineering (Manchester: Manchester 
University Press).

Pestre, D. 2005 "La recherche publique, l'innovation et le social" en Revue Projet 285 (2), 41-51, https://www.cairn.info/revue-projet2005-2-page-51.htm

Rasmussen, W. 1989 Taking the University to the people. Seventy-five years of Cooperative Extension (Iowa: Iowa State University Press).

Ribeiro, S. 2001 "Propiedad intelectual, recursos genéticos y conocimientos tradicionales" en Comercio, Medio Ambiente y Desarrollo Sustentable, pp. 363-380.

Svampa, M. 2013 "Consenso de los Commodities y lenguajes de valoración en América Latina”, Nueva Sociedad, 244, pp. 30-46.

Teubal, M. 2001 “Globalización y nueva ruralidad en América Latina” en Una nueva ruralidad en América Latina (Buenos Aires: CLACSO), 45-65.

Vercellone, C. 2011 Capitalismo cognitivo. Renta, saber y valor en la época posfordista (Buenos Aires: Prometeo). 